Córima, Revista de Investigación en Gestión Cultural

ISSN electrónico: 2448-7694

Universidad de Guadalajara

Sistema de Universidad Virtual

México

corima@udgvirtual.udg.mx

Año 3, número 4, enero-junio 2018

\title{
Tendencias, retos y tensiones globales de la gestión cultural y su formación. Entrevista a Lluís Bonet Agustí ${ }^{1}$
}

\author{
Lluís Bonet Agustí \\ Universidad de Barcelona, España \\ Marco Antonio Chávez Aguayo ${ }^{2}$ \\ Universidad de Guadalajara, México
}

DOI: $10.32870 /$ cor.a3n4.7113

[Aceptado para su publicación: 12/12/2017]

\begin{abstract}
Personalmente, mi gran escuela de aprendizaje ha sido América Latina [...] Porque yo soy un europeo distinto gracias a ella
\end{abstract} Lluís Bonet Agustí

\footnotetext{
1 Nota del director: Córima, Revista de Investigación en Gestión Cultural agradece la generosidad del Dr. Lluís Bonet Agustí por concedernos esta entrevista en exclusiva. Fue editada por cuestiones de estilo y videograbada el 4 de diciembre de 2017 en las instalaciones del Sistema de Universidad Virtual de la Universidad de Guadalajara, México, con la colaboración de su Unidad de Comunicación y Difusión, a quienes también les agradece.

2 Correo electrónico: corima@udgvirtual.udg.mx

CÓMO CITAR ESTE ARTÍCULO:
}

Bonet Agustí, L., Chávez Aguayo, M. A. (2018). Tendencias, retos y tensiones globales de la gestión cultural y su formación. Entrevista a Lluís Bonet Agustí. Córima, Revista de Investigación en Gestión Cultural, 3(4). doi: 10.32870/cor.a3n4.7113 
En esta entrevista, el Dr. Lluís Bonet Agustí, coordinador de diversos programas de posgrado en Gestión Cultural de la Universidad de Barcelona (España) desde hace 30 años, explica las tendencias, retos y tensiones globales de la gestión cultural y, en especial, de sus programas de formación en los cinco continentes. Aborda los cambios en los modelos de políticas culturales en Europa y el creciente interés en estrechar las relaciones culturales con América Latina a través de la diplomacia, la cooperación y el empoderamiento y liderazgo de los jóvenes. También habla de los cambios que han ocurrido a nivel mundial en las formas de hacer y enseñar gestión cultural durante las últimas décadas, repasando las primeras experiencias de formación en Latinoamérica, y expone cómo esta región ha sido para él una gran escuela de aprendizaje, puesto que le ha servido para ampliar su perspectiva; además, expresa el deseo de que sus colegas europeos volteen cada vez más hacia allí, alejándose de clichés y trabajando más cercanamente con sus pares latinoamericanos.

Marco Antonio Chávez Aguayo: Desde tu experiencia, ¿cuáles son los retos que ves hoy en la gestión cultural en Europa?

Lluís Bonet Agustí: La gestión cultural en Europa depende en buena medida de la combinación entre el apoyo público, los propios recursos, la capacidad de generar nuevos recursos por parte de los equipamientos, de los proyectos, y al mismo tiempo generar nuevos enfoques en términos de participación, es decir, cómo empoderamos a la gente para que la gente sea la real protagonista de los procesos culturales. Pienso que este instrumento es el reto percibido por parte de muchos como fundamental.

MACA: A lo largo de los años en los que has trabajado en este tema, ¿cuáles cambios has visto en Europa, desde las formas de gestionar hasta las formas de políticas que se hacen alrededor de la cultura?

LBA: Creo que hay dos tipos de cambio. Como has dicho, por un lado en las políticas, Europa desarrolla a partir de los años sesenta el estado del bienestar también en el ámbito de la cultura, aunque sea evidentemente un estado del bienestar más limitado de lo que sería en el mundo de la sanidad o el mundo de la educación. Evidentemente no se dedican los mismos recursos a la cultura que a esos grandes sectores, pero sí que hay ese desarrollo. Primero, basado en la idea de democratización cultural, es decir, hacer llegar la alta cultura a las capas más amplias posibles de la población; por tanto, abrir los equipamientos, abrir las manifestaciones para captar a la gente. Luego, hay un interés importante a partir de los años setenta en que eso se 
complemente con dar valor a la propia expresión cultural de la población -lo que llamaríamos democracia cultural- y eso siempre lo tenemos en relación con ese concepto tan complejo que es el de excelencia, es decir: derechos culturales, excelencia, democratización, y que serán los pilares del estado del bienestar en el ámbito de la cultura.

¿Cómo evoluciona a partir de los años noventa y con el cambio de siglo? Por un lado, aparece ese otro elemento que es el de las industrias culturales y creativas, y la necesidad de fortalecerlas. Por tanto, hay una política específica en ese ámbito que lleva una doble concepción: una que nace desde el nivel estatal y otra que nace desde el nivel local. Eso será muy importante porque la mayor parte del dinero público que va a la cultura en Europa procede del medio local, y en la medida en que el sector local, en que las autoridades locales perciban a la cultura de la ciudadanía como una forma de aproximación a la propia ciudadanía, eso explica el presupuesto. En esa época empieza a haber la necesidad de encontrar nuevos recursos de autofinanciación y se comienzan a hibridar los modelos, es decir, existía el modelo de arts council, de gestión a distancia del mundo anglosajón; también existe el modelo más indirecto de Estados Unidos y que en Europa tiene poca penetración; aunque se estudia e interesa ver hasta qué punto hay una captación importante de recursos propios, en Europa continental se mantiene con fuerza la idea del papel del Estado en sus distintos niveles de gobierno. La crisis económica de finales de la primera década del siglo XXI, sobre todo en el sur de Europa -no tanto en el norte, cuyos recursos son generosos-, donde hay una reducción de los recursos públicos a la cultura, obligará a mirar hacia otros lugares y América Latina será un espacio fantástico de experimentación para ver cómo se pueden hacer cosas con menos dinero. Y eso lleva a plantearse, por un lado, cómo cambiamos las políticas culturales, pero también cómo gestionamos de forma distinta.

Hemos de tener en cuenta que la nueva gestión pública empieza a ser un espacio de reflexión importante para transformar nuestras viejas maneras burocráticas de gestionar lo público. A partir de los años noventa hay también un esfuerzo de apertura, de pensar más en los aspectos de meritocracia, en cómo la gestión pública puede aprender cosas de la gestión privada para estar mejor al servicio de la ciudadanía y vemos que eso también está cambiando. Por último, la auto-organización social tiene un papel importante en el sentido de que es un contrapunto a la forma más institucionalizada de gestionar cultura. Los movimientos comunitarios, alternativos, etcétera, cuestionan lo público, se preguntan por qué lo público debe ser siempre gubernamental. No, lo público, el commons, es algo que se conduce. Vemos que en Europa hay esa evolución, en ese largo período de tiempo, y hay esa apertura hacía nuevos modelos para intentar dar respuesta a los viejos retos. 
Pero, evidentemente, todo eso se hace con tensiones: el mundo artístico, que considera que debería haber más énfasis en la creatividad; el mundo público, que con una mirada, quizá hoy en día más eclética, ya no defiende tanto aquellas formas de expresión cultural que estaban basadas en el concepto de excelencia, o el mundo asociativo que reclama un espacio propio y que no quiere ser una apéndice de las políticas públicas.

MACA: ¿Y cuáles son los nuevos modelos que detectas en este momento en Europa? LBA: Por un lado, la idea de empoderamiento que comentaba antes. Estoy participando en un proyecto de Europa Creativa, que se basa en estudiar, practicar y al mismo tiempo investigar. Es un proyecto mixto de acción-investigación, en el que distintos festivales, distintos teatros de distintas partes de Europa y un grupo de tres centros de investigación analizamos cómo se genera, en el mundo de las artes escénicas -en un mundo que no es virtual-, el prosumer, es decir, ese consumidor y al mismo tiempo productor. Estamos estudiando cómo esto se presenta, por ejemplo, en el ámbito de la programación artística; cómo empoderamos ciudadanos, cómo empoderamos gente joven para que programe, para que produzca, para que co-cree, para que de alguna forma asuma responsabilidades y compromiso. Eso evidentemente genera tensiones, sobre todo con aquellos teatros o aquellos festivales más anclados en el pasado donde la figura del director artístico como dios aún existe. El propio concepto de excelencia, en particular en Europa del este se ve como un peligro. La pérdida del aura. Creo que, en cambio, en el mundo anglosajón europeo es donde se ha avanzado más y se han generado experiencias geniales. Y quizá en el mundo latino de Europa estamos a mitad de camino. Es un tema que está creciendo en este momento. Hay una enorme cantidad de gente preocupada por el aspecto social, por la dimensión social y el impacto social de la cultura. Esto es algo relativamente nuevo. Es algo que en América Latina ha sido una constante, pero que en Europa no era tan importante y ahora está siendo realmente sustantivo.

MACA: Este proyecto que comentas, ¿es un proyecto solo europeo o involucra también a otras regiones?

LBA: Este en particular, que se llama Be Expectative, sobre espectadores de las artes escénicas, es un proyecto de Europa Creativa; por tanto, es un proyecto europeo con socios en el Reino Unido, Rumanía, Hungría, Croacia, Italia, Francia, España...

MACA: En este y otros proyectos relacionados con la gestión cultural, ¿cómo se ve a Latinoamérica, sus recursos, sus personas?

LBA: Estoy coordinando un gran proyecto de investigación, financiado por el programa Horizonte 2020, que es el gran programa de investigación de la Unión Europea. Es un programa que analiza las relaciones sociales, culturales y científicas 
entre la Unión Europea y América Latina y el Caribe. En este programa, las relaciones culturales es el tema que a mí personalmente más me interesa. Es un programa grande con diecinueve partners en Europa y América Latina. En Latinoamérica tenemos a Chile, Argentina, Brasil, Ecuador, Centroamérica, el Caribe no hispanohablante; en Europa también tenemos socios en Alemania, Austria, Holanda, Francia, Italia, República Checa. La intención es responder cuáles son las barreras y cuáles son las potencialidades para hacer crecer esa relación. Esto parte de la idea de la diplomacia pública europea, en el sentido de decir: Europa debe abrirse, ha de hacer una diplomacia soft, sin coartar las iniciativas de todo el mundo. Porque pretender que los Estados tienen el monopolio de las relaciones internacionales es una mirada absolutamente desfasada. Lo que está claro es que puedes incentivar que haya esa relación con recursos, normativas, acuerdos de coproducción, etcétera. Y desde Europa, América Latina se ve como un espacio con el que se comparten la mayor parte de los valores. En un mundo con un cambio tan fuerte en el que tenemos a China, Estados Unidos, algunos partners, donde las relaciones de fuerza están cambiando; tanto América Latina como la Unión Europea se basan en el concepto de relaciones multilaterales, es decir, son territorios en el que no se cree en el domino de uno grande y fuerte sobre los demás. O sea, Alemania, que sería el país más fuerte de la Unión Europea, no deja de ser uno de los 28 países miembros. En América Latina también existe esa idea, ese respeto al otro. Creo que son valores que compartimos $y$, por lo tanto, todo aquello que favorezca a que las relaciones culturales, sociales y científicas entre estas dos grandes regiones del mundo se comprometan es un punto muy positivo. Y estamos ahí investigando sobre ese tema.

MACA: ¿Qué otros valores notas que se comparten, sobre todo en el ámbito cultural? LBA: En el ámbito cultural es evidente que los idiomas que se hablan en América Latina y el Caribe son idiomas de origen europeo por razones [históricas] que quizá no nos gusten mucho. La colonización y las migraciones. No solamente es la colonia, es el enorme flujo de europeos que llegan a América Latina y el Caribe durante esos quinientos años, pero que, sobre todo a partir del siglo XIX y el siglo XX, han sido movimientos migratorios enormes. Eso hace que haya una relación permanente que se ve en la música, las artes visuales, en las mutuas influencias que tenemos o en la literatura. Para poner un ejemplo, ya que estamos en Guadalajara y acabamos de disfrutar estos días con la Feria Internacional del Libro, está claro que sin la literatura latinoamericana no se entendería la riqueza, el dinamismo de la literatura española $y$, no solamente la literatura española, de buena parte de la literatura occidental que se ve influenciada por ese realismo mágico, por esa capacidad. Entender cómo funciona el sistema editorial, cómo funciona el sistema de derechos de autor, ver las 
diferentes perspectivas sobre esos temas, cómo la digitalización está influyendo. Eso es lo que estamos investigando. No podemos quedarnos con la mirada antigua, sino que hemos de pensar cómo favorecemos las relaciones culturales entre los dos continentes más allá de las áreas lingüísticas de conexión tradicional, es decir, sería negativo para América Latina y para Europa que las relaciones fueran solamente entre la Península Ibérica - por razones lingüísticas obvias- y América Latina. Es evidente que aquí hay una relación mucho más fluida, mucho más fácil, pero ¿por qué no con Italia, Francia, Alemania, etcétera?

MACA: En las últimas décadas has visitado sistemáticamente Latinoamérica, sus distintos países. A lo largo de este tiempo, ¿qué cambios has percibido en la forma de hacer gestión cultural?

LBA: He venido a América Latina desde el año 1991, con lo cual llevo muchos años de venir por acá. Han cambiado muchas cosas. De entrada, el conjunto del continente ha cambiado, no solamente en lo cultural. Yo recuerdo visitar museos y teatros. Por ejemplo, recuerdo el caso de Chile; una sociedad que era muy moderna, que sobre todo en los barrios buenos de Santiago había unos malls y una vida económicamente muy potente y entrabas en los equipamientos culturales y daban pena. Parecía que viajabas al siglo XIX. Eso ha cambiado radicalmente. Hay, en términos de innovación, un tema en el que América Latina está dando lecciones a todo el mundo: la formación artística. Cómo incorporar la comunidad en la formación artística y cómo la formación artística es un elemento de desarrollo social, económico y cultural para comunidades. Creo que eso es fantástico. Es verdad que, por otro lado, las desigualdades sociales son, desde mi punto de vista, el gran reto a superar. Esas desigualdades, tan enormes en algunos casos que tienen evidentemente contrapartidas o reflejos en lo cultural. Es aquí donde miro el gran avance en términos de experimentación; quizá no se ha avanzado tanto en términos de generalización de estas relaciones. En innovación artística y creativa también se están cambiando muchas cosas. En el mundo universitario el cambio es enorme -estoy hablando en términos muy generales-, donde había una pequeña élite de universidades de primer nivel y una mayoría de universidades de muy bajo perfil, ves cómo las cosas están cambiando. Se están formando profesionales y hay un dinamismo muy potente. En las relaciones científicas empezamos a tener unos partners de igual a igual. Están haciendo investigaciones conjuntamente europeos y latinoamericanos. $Y$ eso ha cambiado mucho porque también los países han cambiado. En general, la mirada, la evolución, es muy positiva.

MACA: También han sido décadas de coordinar programas de formación en Gestión Cultural. Me gustaría saber, desde el programa que coordinas y desde Europa, ¿cuáles 
son los retos ahora de la formación?, ¿cuáles serían los retos principales para ti en la formación de la Gestión Cultural en esta época o en este año?

LBA: En el ámbito de la formación, América Latina no es pionera; pero si nos vamos hacia atrás, hay dos o tres experiencias que son muy antiguas. Lo que ha pasado es que no ha habido continuidad. Getúlio Vargas empieza en los años setenta con un programa de formación de líderes culturales un poco elitista, en el sentido de que llega a personas muy concretas; pero hace un trabajo muy importante. En Venezuela, el CLACDEC también hizo un buen trabajo. En Colombia, ya desde los años noventa la Universidad del Rosario está haciendo formación en Gestión Cultural. En el caso mexicano hay un trabajo de base que Conaculta empuja desde los años noventa. Con lo cual hay formación. Pero el gran cambio se da con la explosión de programas en el ámbito de la gestión cultural que nacen en países como Argentina a partir de mediados de los años noventa y principios del siglo XXI. En ese momento hay una enorme oferta en Chile, que por el tamaño del país tiene una variedad de programas. Países pequeños, como Uruguay, tienen buena formación. Ya no hablemos del caso de Brasil, Colombia o Ecuador, que en ese momento también está desarrollándose. Todos los países evolucionan en muy buena sintonía.

Quizá los retos están en generar mecanismos de formación crítica que hagan que nuestros profesionales estén capacitados para adaptarse al cambio permanente $y$, al mismo tiempo, que sean capaces de leer esas lógicas sobre la existencia de una política cultural que es relativamente clientelar, que hay estructuras muy burocratizadas y eso no desaparece, aunque estemos en un mundo digitalizado, aunque tengamos retos. Entonces, la capacidad para formar críticamente a gente que sea capaz de moverse en esos distintos planos, para mí es el gran reto. Cómo nosotros como formadores ayudamos a los profesionales a esa adaptación permanente y cómo conseguimos que las nuevas generaciones, que están mejor formadas que las viejas generaciones, entablen una relación intergeneracional positiva. Porque, por ejemplo, en términos de género, vemos cómo delante de las grandes organizaciones culturales en América Latina -también pasa en Europa- hay fundamentalmente hombres y realmente hay pocas mujeres. En cambio, en la base dominan las mujeres. Cuando ves, por ejemplo, cómo en algunos lugares hay miradas un poco jerárquicas, anticuadas, a veces con un discurso un poco hipócrita, entre populistas por un lado y neoliberales por el otro. Nuestra función es justamente ayudar a la gente a tener esa mirada crítica, pero al mismo tiempo muy constructiva, capaz de adelantar procesos y conseguir esa gota malaya que hace que las cosas avancen y avancen, que cada grano de arena cuente, y que finalmente consigamos que la cultura ayude a transformar nuestras sociedades. Dos o tres grandes mundos 
poco conectados entre sí; un mundo muy competitivo internacionalmente, un mundo muy proteccionista e institucional gremial -a veces te sorprende ver en un país tan avanzado la cantidad de gente que puede estar trabajando en una cosa que podrían hacer con menos-, y luego están esas iniciativas más sociales con una cultura tradicional muy potente de la que están orgullosos.

Esa es la realidad, que si la contrasto, por ejemplo, con Sudáfrica, donde después de la gran revolución que significó el fin del apartheid, el gran drama es la enorme diferencia social que existe, pero no solo entre blancos y negros, es también entre negros donde hay unas diferencias económicas sociales enormes. De alguna forma, Sudáfrica me recordó un poco América Latina, aunque ahí los retos son mucho más grandes por la enorme diversidad de lenguas, de culturas que conviven en un mismo territorio. El número de lenguas oficiales es enorme, aunque el inglés es la lengua coiné, la lengua de conexión y de interacción. Hay grandes esfuerzos para superar las tensiones entre comunidades, pero esas tensiones existen. Entonces, toda la idea de la diversidad cultural es enormemente importante, por esa misma diversidad, porque es una respuesta.

Este caso, si ahora lo comparara con Singapur, que es un país donde la cultura juega un papel fundamental, no diré decorativo, pero sí de alguna forma de una cultura aséptica, poco comprometida, glamurosa, comercial, con una biblioteca nacional maravillosa.

MACA: ¿Es más elitista?

LBA: Sí, elitista; pero al mismo tiempo, a veces no cumpliendo suficientemente bien el papel crítico que le toca jugar a la cultura. Pretenden atraer turismo rico de la región. Entonces, el tipo de programación que hacen en los teatros y en los museos con mucho dinero es de enorme calidad técnica, pero yo diría que poco enraizada, porque no deja de ser una especie de gran aparador para atraer a esa gente.

O, por ejemplo, un caso muy interesante es lo que está sucediendo en Hong Kong; pero al mismo tiempo con un sistema económico y político distinto. O lo que está pasando en Taiwán. Esas relaciones en China son muy interesantes de ver. En términos de gestión cultural, por ejemplo, en Taiwán están en este momento desarrollando grandes escuelas de formación en Gestión Cultural. Lo mismo en Hong Kong. Mucha gente del mainland, de la China continental va a estudiar a Hong Kong, aunque es carísimo, porque los precios que pagan...

MACA: Será restrictivo, ¿no?

LBA: Restrictivo. Aunque debemos pensar que en China hay mucha gente muy rica. MACA: Habrá muchos pobres por eso también. 
LBA: También, pero la República Popular China, ahí también está el boom enorme del mundo de la gestión cultural. Es bestial. Están creando teatros, están creando de todo. El número de cursos de formación en Gestión Cultural que están creándose en China es apabullante y cada año hay nuevos. Van a una velocidad que nosotros los del viejo continente no podemos entender, porque realmente somos viejos al lado de su dinamismo. Otra cuestión es el nivel de profundidad, el nivel de capacidad crítica, el nivel de interacción entre sectores. Creo que esa dimensión de lo comercial es muy predominante.

MACA: Finalmente, identificas distintas tendencias a la hora de la formación. Enfoques más inclinados hacia un lado o al otro en estos países, en estas distintas regiones del planeta, incluida Latinoamérica.

LBA: Sí. Como pasó en su momento en Europa del este después de la caída del muro, que miran más al modelo gringo ${ }^{3}$ que al modelo europeo occidental, porque de alguna forma van a la búsqueda de resultados inmediatos y el marketing, las herramientas de financiación. Esas técnicas son las que les atraen y quieren implementar en sus propias políticas, aunque lentamente se van dando cuenta. Por ejemplo, yo acabo de ver que nuestro libro de gestión de teatros, de modelos y estrategias para gestionar equipamientos culturales acaba de ser traducido al rumano. Cuando le pregunté al Ministerio de Cultura de Rumania por qué les había interesado traducir el libro (que es un libro escrito con Héctor Schargorodsky de Buenos Aires, donde intentamos recoger la experiencia latina de Europa y la experiencia latina de América) me decían: Es que nos interesa mucho porque buena parte de los problemas que nosotros tenemos se parecen mucho más a la realidad latinoamericana que a la gringa, porque tenemos grandes teatros, grandes estructuras muy burocratizadas y luego tenemos un sector marginal con muy pocos recursos, ese teatro alternativo. $Y$ eso se replica en lo audiovisual, en las artes visuales y el modelo que vosotros estáis explicando e intentáis no dar recetas, pero sí plantear preguntas, es enormemente más útil que el modelo gringo que en el fondo nace de una mirada hegemónica del mundo.

Ellos [los estadounidenses] creen que el mundo es como ellos y América Latina sabes perfectamente que no es en absoluto homogénea. Alguien que pretenda que del Río Grande hasta la Patagonia o la Tierra del Fuego las cosas son iguales es que no entiende en absoluto América Latina. Creo que nuestro libro tiene esa capacidad y eso lo ves en esas tendencias, en ese decir: ¿qué es lo que necesitamos para formarnos, por ejemplo, en términos de indicadores de evaluación? Un tema que nosotros hemos trabajado bastante. Es evidente que puedo tener una mirada

\footnotetext{
${ }^{3}$ Se refiere al modelo estadounidense.
} 
tecnocrática sobre la evaluación en la cultura o puedo tener una mirada en la que escuche qué es lo importante, cuáles son los indicadores importantes para un director artístico, en términos de la evaluación de su trabajo y de sus objetivos; cuáles son los indicadores importantes para un responsable de la parte educativa de un museo, de un teatro, de una galería de arte, de una editorial; qué es aquello que le interesa a un productor. Entonces, cuando eres capaz de plantear de forma multidimensional una evaluación que sea útil para todas esas distintas personas, esos distintos profesionales que están juntos, es enormemente interesante. Esto está ligado a otro aspecto que es para mí fundamental y que estamos ahora empezando a trabajar en un nuevo proyecto internacional, que es el tema del liderazgo, de los modelos de liderazgo en el ámbito de la gestión cultural. Porque nosotros empezamos trabajando el tema de lo que Ilamamos el doble liderazgo, artístico-gerencial, que es común en muchas organizaciones culturales: alguien que lleva más la dirección artística y alguien que lleva más la dirección gerencial. Uno más visible, más de cara afuera, que es el artístico; alguien más de cara adentro, que es el gerencial. Pero empezamos a ver que hay muchos otros modelos y estamos trabajando con un grupo de universidades europeas. Vamos a intentar montar un proyecto sobre ese tema y todo el tema del liderazgo.

Yo formo parte, además, de un proyecto de la Unión Europea de diplomacia cultural, que es el programa de jóvenes líderes culturales en el que invitamos cada año a treinta líderes jóvenes culturales de diez países del mundo: Estados Unidos, Canadá, Sudáfrica, Brasil, México, China, Japón, Corea, India y Australia, y diez jóvenes líderes culturales europeos. Los estamos mezclando y trabajamos durante una semana juntos para generar sinergias-puentes. Es enormemente interesante porque somos cinco animadores docentes de ese trabajo conjunto, de esos cuarenta jóvenes líderes culturales de todas partes del mundo y para mí es interesantísimo estar metido ahí, ser el viejito de ese grupo de gente joven, animándoles y viendo cómo plantea en términos de liderazgo las cosas un coreano o un japonés; un brasileño o un mexicano, o un hindú. Los hindúes son de un mundo fascinante. Es para mí una experiencia fantástica que intento después que mis alumnos de la Universidad de Barcelona puedan recoger de alguna forma, o intento contarles cómo están pasando las cosas en el resto del mundo. Porque el planeta se ha hecho muy chiquitito y no podemos continuar, yo desde Cataluña, pensando que las cosas se hacen desde nuestra pequeña realidad, sino que debo ser capaz de contarle a alguien que trabaja con una comunidad local en Cataluña que el mundo es su mundo y su comunidad. Al mismo tiempo que han de estar al servicio de la cultura tradicional, de 
la vanguardia, del trabajo comunitario. Al trabajar en red, desde lo micro podemos trabajar en red a nivel global.

MACA: Claro. Esta consciencia de la diversidad y de la globalidad... Por cierto, aquí hay un gran número de personas que opinan que en Latinoamérica miramos mucho a Estados Unidos. Otros opinan, sobre todo en la gestión cultural, que miramos mucho hacia Europa. Quizás haya unos terceros que identifiquen un modelo propio, pero ¿tú cómo lo consideras?, ¿o ves un cambio, que al principio haya sido de una manera y después de otra?

LBA: Yo debo decir que para mí, personalmente, mi gran escuela de aprendizaje ha sido América Latina.

MACA: ¿Por qué?

LBA: Porque yo soy un europeo distinto gracias a América Latina y eso le decía un día a Néstor García Canclini, que su introducción al libro de Bourdieu, La Distinción, me abrió, porque yo podía entender la distinción. Yo fui formado en la cultura francesa. Para un catalán el francés es muy próximo. Por lo tanto, la cultura francesa y los intelectuales franceses han sido siempre para nosotros un gran referente y yo podía entender muy bien a Bourdieu. Pero cuando leí la introducción de Néstor García Canclini a Bourdieu y cómo lo contextualizaba en América Latina, a mí eso, como intelectual, como académico europeo, me abrió un mundo fantástico. He aprendido tantas cosas en América Latina y eso es lo que trato de hacer. Intento hacer de puente, en mis viajes, en mi formación, explicar a los europeos la cantidad de cosas que podemos aprender de América Latina. Es una enorme escuela para nosotros. Por lo tanto, creo que eso es lo importante: ese flujo. Que América Latina mire a Europa y a Estados Unidos es genial, pero conseguiremos que los europeos miren también a América Latina, porque igualmente nosotros ahora estamos mirando mucho a Asia y empezamos a mirar demasiado poco, de momento, hacia África. En África, por ejemplo, acaban de constituir una red -ya existía previamente una red liderada por la UNESCO sobre temas de política cultural africana-, y eso ha dado un paso de gigante; en este momento hay una cosa súper dinámica, en la que estoy leyendo a mis colegas africanos sobre cómo están las cosas cambiando, cómo las ven ellos. En general los europeos tenemos el problema de que nos conocen mucho mejor los de fuera que nosotros a los de fuera: etnocentrismo. Creo que justamente lo que está empezando a cambiar en Europa es la consciencia de que ya no somos el centro del mundo -quizás lo fuimos cuando éramos grandes metrópolis coloniales-. Entender que en el resto del mundo está la riqueza y que nosotros lo que podemos aportar como europeos es la experiencia multilateral; la capacidad de construir gobernanza y 
una sociedad en el respeto al otro, en el que nadie domina al otro, sino que las cosas se hacen por coproducción, por cooperación, por compromiso.

MACA: ¿Cómo ve ahora Europa a América Latina?, ¿cómo lo ven tus colegas, las universidades que conoces, la misma Universidad de Barcelona?

LBA: Hay enormes diferencias. Más allá de la proximidad lingüística -que evidentemente para nosotros América Latina es muy fácil, porque el hecho de hablar castellano o portugués te facilita mucho las cosas-, solo en el mundo occidental de Europa (Italia, Francia, Reino Unido, Alemania, Holanda, los países nórdicos) hay un interés creciente hacia América Latina, interés que, en cambio, no veo en mis colegas -con excepciones- de Europa central y del este. Cuesta ver en los checos, los húngaros, los búlgaros, los rumanos, etcétera, esa mirada. Ven a América Latina desde un cliché. Tenemos un trabajo que hacer los europeos que tenemos este contacto con América Latina. Ese es un primer elemento que sabremos superar. También hemos de ser capaces de superar el hecho de que la atención la acaparan unos pocos países latinoamericanos, o sea, Brasil, México, Colombia, Argentina, Chile... América Latina es mucho más que eso: Centroamérica, pero también países pequeños y que en este momento son muy dinámicos como pueden ser Ecuador, Uruguay, que siempre han sido países muy abiertos a lo internacional. Desde Europa aún hay mucho trabajo de apertura mental y este es un trabajo lento de ir picando piedra que los que tenemos la suerte de tener esta relación profunda, emotiva y de aprendizaje con América Latina debemos intentar convencer y animar a nuestros colegas que miren más y trabajen más con Latinoamérica. 